\title{
Original Article \\ Investigation of Indoor and Outdoor Air Quality at Elementary Schools in Hanoi, Vietnam
}

\author{
Hoang Anh Le ${ }^{1, *}$, Vu Thi Quynh Linh ${ }^{2}$ \\ ${ }^{I}$ Faculty of Environmental Sciences, VNU University of Science, Vietnam National University, Hanoi, \\ 334 Nguyen Trai, Thanh Xuan, Hanoi, Vietnam \\ ${ }^{2}$ Vietnam Environment Administration (VEA), Ministry of Natural Resources and Environment (MONRE), \\ 10 Ton That Thuyet, Nam Tu Liem, Hanoi, Vietnam \\ Received 30 January 2020 \\ Revised 05 March 2020; Accepted 09 March 2020
}

\begin{abstract}
Indoor air quality is having insufficient attention despite its importance for human health, especially for schools because children is one of the most sensitive groups to air pollution. This study focuses on monitoring the air quality inside classrooms at some elementary schools (ELS) of Hanoi with representative parameters including $\mathrm{PM}_{2.5}, \mathrm{PM}_{10}, \mathrm{CO}_{2}, \mathrm{NO}_{2}$, and VOCs. Simultaneously, those parameters in school yards are also monitored to provide data for comparison and evidence of the sources of indoor pollution. The results indicated that the main air quality issue in schools is particulate matters, particularly $\mathrm{PM}_{2.5}$. It also showed that schools locating near traffic roads have concentrations of 2 - 3 times higher than standards. VOCs concentration levels are high indoor and in school yards located near markets and traffic roads. $\mathrm{CO}_{2}$ and $\mathrm{NO}_{2}$ indoor concentrations are below standards in all schools. The ELS-7 has most of indoor and in yards concentrations at the highest values. Two significant factors effecting air quality of schools are traffic and activities of residential areas around them.
\end{abstract}

Keywords: Indoor air quality, School, Vietnam.

\section{Introduction}

Most of people are being aware of the impacts of ambient air pollution to the landscape, biosystem, and human lives. However, not many people know that indoor air pollution (IAP) could also have similar impacts to its objectives. The term "indoor" could be understood as the object that has a boundary with very limited direct ventilation with the surrounding environment. The ventilation could be done mostly by indirect air exchange by man-made

\footnotetext{
* Corresponding author:

E-mail address: leha@vnu.edu.vn

https://doi.org/10.25073/2588-1094/vnuees.4550
} 
facilities such as fan and air conditioner. Some examples of indoor environment could be named as houses, offices, classrooms, commercial buildings, stations, multi-purpose buildings, and car, bus, subway inner, etc. [1-4]. Statistic data prove that human activities spend $87 \%$ of time living inside closed buildings and $6 \%$ inside closed vehicles [5]. Today, people are living in indoor environment in long time and it could become a risk if indoor air quality (IAQ) is not ensured in a safe level of indoor microenvironments $[3,5]$. There are many sources of IAP in any home. These include combustion sources such as oil, gas, kerosene, coal, wood, and tobacco products; building materials and furnishings as diverse as deteriorated, asbestoscontaining insulation, wet or damp carpet, and cabinetry or furniture made of certain pressed wood products; products for household cleaning and maintenance, personal care, or hobbies; central heating and cooling systems and humidification devices; and outdoor sources such as radon, pesticides, and outdoor air pollution [1-6]. IAP could have significant impacts to human health including direct and acute impacts (e.g. eye, nose, throat allergy, headache, dizzy and other tired symptoms) as well as other indirect and chronic impacts (e.g. respiratory diseases, cancer or serious asthenia or death) [7]. World Health Organization (WHO) reported noticeable figures of the estimation of mortality caused by outdoor environment (3.7 mil. people) and indoor environment (4.3 mil. people) [8]. Indoor related mortality are found in low income countries where there is a significant use of pollution containing energy sources [1-8].

Studies on environmental quality, in general, and air quality, in particular of the mega cities showed that their micro-environments is alarming. Air pollution index of Hanoi city is high, especially PM with concentrations of $1-2$ times higher than Vietnam National Ambient Air Quality Standards (VN AAQS) [9]. The PM concentrations at some traffic conjunctions and construction sites are 5 - 6 times higher than VN AAQS [10-12]. Washington State Department of Health gave a warning that indoor pollutants could be far exceeding outdoor pollutants. Some indoor pollutants are having increasing trends in terms of concentration, including: formaldehyde (HCHO), volatile organic compounds (VOCs), radon, fungi and bacteria, by-products of combustion as carbon monoxide (CO), nitrogen oxides $\left(\mathrm{NO}_{\mathrm{x}}\right)$ and particulate matters (PM) [4]. Children are more vulnerable to the adverse health effects of air pollutants than adults because their defense mechanisms are still developing and they inhale a larger volume of air per body weight $[1,3,4,13-15]$. IAP might be a source of increasing of students' eye and skin diseases, decreasing of teachers' productivity, and degradation of studying environment [4]. Since there is no production process, the main sources of air pollution in classes are from construction materials, furniture and the lack of ventilation [7,13-15].

While the effects of IAP on health have been studied extensively in many countries, especially in developed countries, but very limited in Vietnam. There are studies reported about the IAP level in complex building in urban area [16], kitchen room at rural area [17], and traffic mode (public bus) [18]. However, no published to present about air pollution level for indoor classrooms. School buildings are one of the most important indoor environmental quality issues today because children spend the most of their time in these buildings second to home; In additional, schools have high population density, poor ventilation, lack of maintenance, and unsatisfactory cleaning are common, and there are unique sources of pollution leading to very high pollutant concentrations compared to outdoors. Thus, concentration level of some typical pollutants $\left(\mathrm{PM}_{2.5}, \mathrm{PM}_{10}, \mathrm{VOCs}, \mathrm{CO}_{2}\right.$, $\mathrm{NO}_{2}$ ) of both indoor and in the yards (outdoor) are monitored in ten ELS of Hanoi. Those concentration levels are used for comparison of pollution at different sites and as an evidence for IAP in school classrooms.

\section{Methods}

The indoor and outdoor air quality investigations at each school were carried out 
from 19 March to 04 April 2013. Monitoring was set up simultaneously in classrooms and in the yards of those schools with equipment of at least $1.5 \mathrm{~m}$ above the ground. Details of each sampling site and site specific parameters are listed in
Table 1. Time to monitoring started at around 7:30 am to warm-up equipment and the monitoring started at 8:00 am for all sites to cooperation. The number of sample ranged 63 80 depending on school (Table 1).

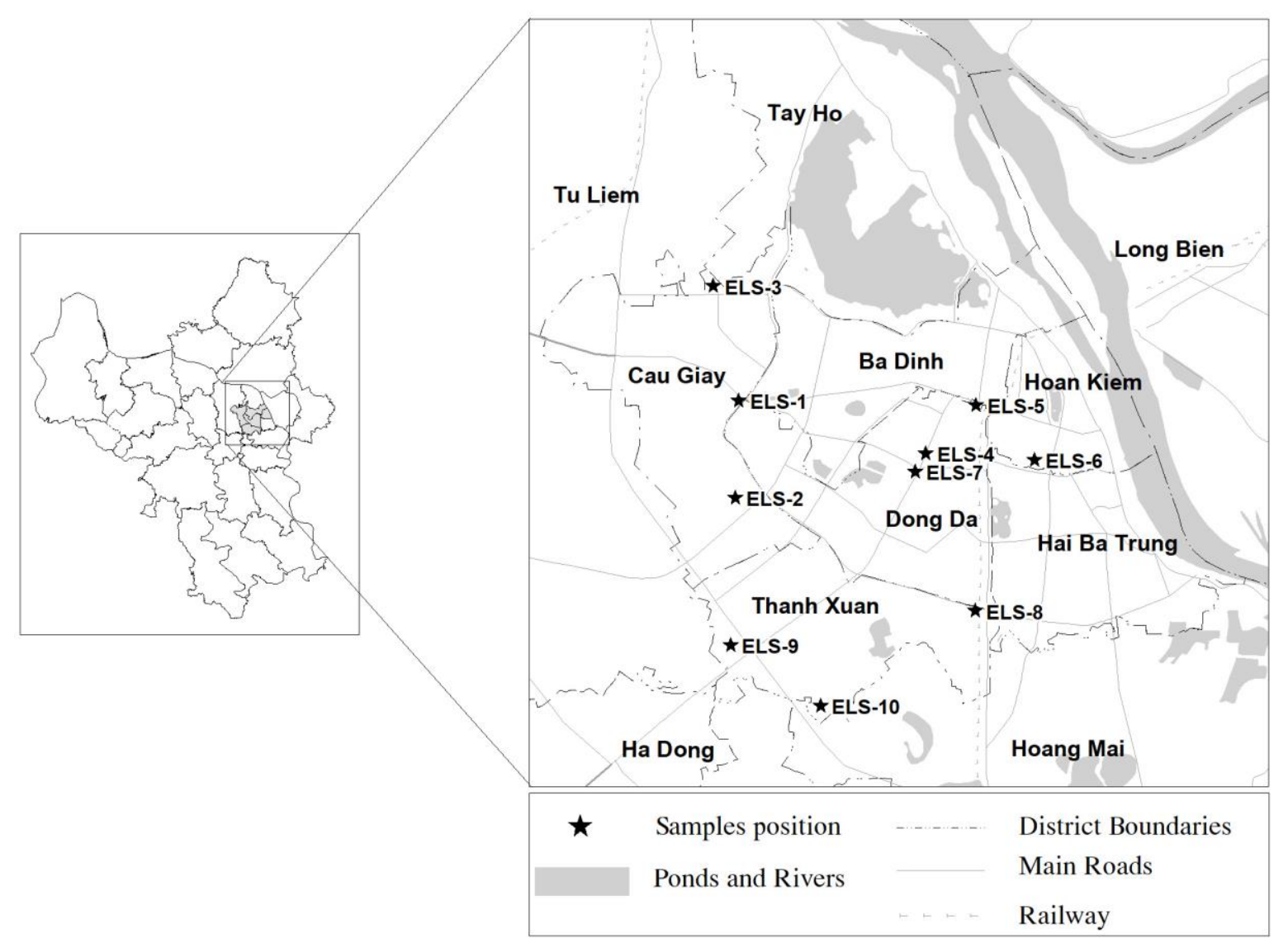

Fig. 1. Schematic diagram on the sampling locations and surrounding area.

Table 1. Detail sampling parameters at each school

\begin{tabular}{lcccccccccc}
\hline & ELS-1 & ELS-2 & ELS-3 & ELS-4 & ELS-5 & ELS-6 & ELS-7 & ELS-8 & ELS-9 & ELS-10 \\
\hline Floor area $\left(m^{2}\right)$ & 62.2 & 58.4 & 56.3 & 61.6 & 48.7 & 43.3 & 55.2 & 57.8 & 47.9 & 65.1 \\
Room volume $\left(m^{3}\right)$ & 188.4 & 205.6 & 189.2 & 196.2 & 163.6 & 167.6 & 196.2 & 188.4 & 160.4 & 208 \\
Indoor sampling floor & 1 & 2 & 2 & 2 & 1 & 1 & 1 & 2 & 1 & 1 \\
Number of samples & 63 & 66 & 74 & 69 & 77 & 76 & 70 & 72 & 80 & 68 \\
Number of students & 42 & 38 & 36 & 48 & 32 & 33 & 37 & 40 & 35 & 40 \\
occupying classroom & & & & & & & & & \\
Mode of ventilation & WAC & WAC & CF & CF & CF & CF & WAC & WAC & CF & CF \\
\hline
\end{tabular}

Note: WAC: Window type air conditioning; CF: Ceiling fan 
Five air pollutant components including $\mathrm{PM}_{2.5}$ (particulate matters with aerodynamic diameter less than $2.5 \mu \mathrm{m}$ ), $\mathrm{PM}_{10}$ (particulate matters with aerodynamic diameter less than 10 $\mu m)$, VOCs, $\mathrm{CO}_{2}, \mathrm{NO}_{2}$ were simultaneously monitored in classrooms and in the yards of 10 ELS in Hanoi (Fig. 1) where surrounding contexts were relatively different (Table 2).

A Q-TRAK (TSI, model 8552) was used for $\mathrm{CO}_{2}$ measurement. A PpbRAE parts per billion Volatile Organic Compound Monitor (Model PGM-7240) was used for VOCs measurements. Indoor and outdoor $\mathrm{PM}_{10}, \mathrm{PM}_{2.5}$ levels were measured using a TSI DUSTTRAK ${ }^{\mathrm{TM}}$ Aerosol Monitor Model 8520. The $\mathrm{NO}_{2}$ was measured by $\mathrm{NO}_{\mathrm{x}}$ Monitor Model $405 \mathrm{~nm}$. The sampling equipment were calibrated at the environmental laboratory of Faculty of Environmental Sciences (FES) before use. Due to the lack of standards for IAQ in classroom, the allowance standards for $\mathrm{PM}_{2.5}, \mathrm{PM}_{10}, \mathrm{NO}_{2}$ of "Indoor Air Quality Standard - Draft version", submitted by Ministry of Health ( $\mathrm{MOH})$, were used for assessment. However, $\mathrm{CO}_{2}$ and VOCs concentration values were assessed basing on international standards.

Table 2. Characteristics of sampling sites

\begin{tabular}{|c|c|}
\hline Element school ID & Location characteristics \\
\hline ELS-1 & Near the roads of central city with relatively low intensity of traffic \\
\hline ELS-2 & Inside a residential area of central city \\
\hline ELS-3 & Inside a residential area, with a distance to city center \\
\hline ELS-4 & $\begin{array}{l}\text { Near the roads of central city with high traffic intensity and crowded } \\
\text { commercial activities }\end{array}$ \\
\hline ELS-5 & Near the main road of central city with high traffic intensity \\
\hline ELS-6 & $\begin{array}{l}\text { Near the roads of central city with high traffic intensity and crowded } \\
\text { commercial activities }\end{array}$ \\
\hline ELS-7 & $\begin{array}{l}\text { Near the roads of central city with high traffic intensity and crowded } \\
\text { commercial activities }\end{array}$ \\
\hline ELS-8 & Inside a residential area of central city \\
\hline ELS-9 & Near the roads of a newly developed area \\
\hline ELS-10 & $\begin{array}{l}\text { Near the roads with relatively low intensity of traffic, with a distance to city } \\
\text { center }\end{array}$ \\
\hline
\end{tabular}

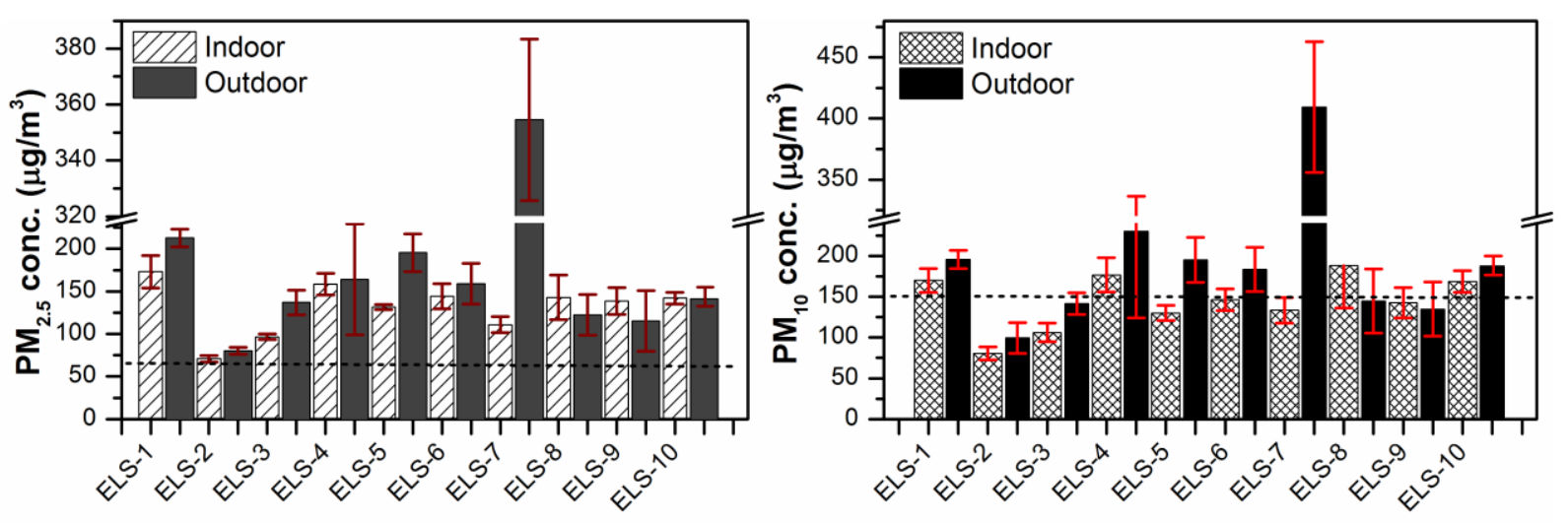

Fig. 2. Average hourly concentration levels of $\mathrm{PM}_{2.5}, \mathrm{PM}_{10}$ at indoor (red) and outdoor (black) schools; Dash lines (---) are IAS of $\mathrm{PM}_{2.5}\left(65 \mu \mathrm{g} / \mathrm{m}^{3}\right)$ and $\mathrm{PM}_{10}\left(150 \mu \mathrm{g} / \mathrm{m}^{3}\right)$ [3]. 


\section{Results and discussion}

\subsection{Concentration levels of particulate matters}

Fig. 1 shows the indoor and outdoor $\mathrm{PM}_{2.5}$ and $\mathrm{PM}_{10}$ levels measured at the ten classrooms. The overall average concentration levels ( \pm standard deviation) of $\mathrm{PM}_{2.5}$ (indoor), $\mathrm{PM}_{2.5}$ (outdoor), $\mathrm{PM}_{10}$ (indoor), and $\mathrm{PM}_{10}$ (outdoor) were $131 \pm 30.9 \mu \mathrm{g} / \mathrm{m}^{3}, 168.5 \pm 78.4 \mu \mathrm{g} / \mathrm{m}^{3}$, $144.1 \pm 44 \mu \mathrm{g} / \mathrm{m}^{3}$, and $192.6 \pm 95.1 \mu \mathrm{g} / \mathrm{m}^{3}$, respectively. The highest levels of $\mathrm{PM}_{2.5}$ and $\mathrm{PM}_{10}$ indoor were $173 \mu \mathrm{g} / \mathrm{m}^{3}$ and $188.3 \mu \mathrm{g} / \mathrm{m}^{3}$ at ELS-1 and ELS-8, respectively. While the highest levels of $\mathrm{PM}_{2.5}$ and $\mathrm{PM}_{10}$ outdoor were $354.6 \mu \mathrm{g} / \mathrm{m}^{3}$ and $409.5 \mu \mathrm{g} / \mathrm{m}^{3}$ monitored at ELS7 , respectively. Particulate matte $\left(\mathrm{PM}_{2.5}, \mathrm{PM}_{10}\right)$ in classrooms and in the yards of schools are correlated (Fig. 2). It should be noted that indoor $\mathrm{PM}_{2.5}$ concentrations of all sites are over indoor air quality standard (IAS) by $65 \mu \mathrm{g} / \mathrm{m}^{3}$ [3], but lower than those found in Izmir, Turkey (452 \pm $177 \mu \mathrm{g} / \mathrm{m}^{3}$ ) [15]. Indoor $\mathrm{PM}_{10}$ of some schools (i.e. ELS-1, ELS-4, ELS-8, ELS-10) are slightly higher than the IAS by $150 \mu \mathrm{g} / \mathrm{m}^{3}$ [3]. Schools located in residential areas (i.e. ELS-2, ELS-3) have lower PM concentrations than schools located near the roads. The schools located near high traffic intensity have PM concentrations of 2 - 3 times higher than the standard, and in some cases, there are additional impacts from commercial and production activities. Fine particles $\left(\mathrm{PM}_{2.5}\right)$ concentrations indoor higher than those in outdoor, e.g. at ELS-8 and ELS-9 sites. The reasons for this might be varied, for instance, movement of students in break time can make particles emitted and dispersed in the air, especially fine particles. There was a significant high concentration of $\mathrm{PM}$, both $\mathrm{PM}_{2.5}$ and $\mathrm{PM}_{10}$, in the yard of ELS-7 which was noted as the contribution of a construction works of nearby residential areas. Average indoor (classroom micro-environment) temperature ranged from $24^{\circ} \mathrm{C}$ to $26.2^{\circ} \mathrm{C}$ while the outdoor (ambient micro-environment) temperature ranged from $22^{\circ} \mathrm{C}$ to $32^{\circ} \mathrm{C}$. ASHRAE suggested the indoor temperature should be $19^{\circ} \mathrm{C}$ to $23^{\circ} \mathrm{C}$ in the winter [19]. The indoor temperature in this study is slightly higher than the recommended level, but temperature is difficult to control at naturally ventilated classrooms [13]. Indoor relative humidity $(\mathrm{RH})$ varied between $70 \%$ and $86 \%$, and outdoor RH varied between $75 \%$ and $98 \%$. Wind speed indoor and outdoor classrooms are ranged $0-0.7 \mathrm{~m} / \mathrm{s}$ and $0.2 \mathrm{~m} / \mathrm{s}-1.4 \mathrm{~m} / \mathrm{s}$. Variation of PM, and other common air pollutants, depends on the emission sources, location, and several meteorological conditions (i.e. wind speed, wind direction) $[10,13]$.

\subsection{Concentration level of $\mathrm{CO}_{2}, \mathrm{NO}_{2}$}

Fig. 3 shows the variation of indoor and outdoor $\mathrm{CO}_{2}$ and $\mathrm{NO}_{2}$ concentrations on a typical sampling day. $\mathrm{NO}_{2}$ concentration indoor is lower than outdoor due to its emitted sources as from anthropogenic activities, especially from the use of vehicles (Fig. 1). The highest levels of $\mathrm{NO}_{2}$ indoor and outdoor are $66.6 \mathrm{ppb}$ and $97.7 \mathrm{ppb}$ at ELS-6 and ELS-7, respectively. ELS-5, ELS-6 and ELS-7 have the highest concentrations of $\mathrm{NO}_{2}$ and the most convincing reason is that they are located close to the roads with high traffic intensity.

$\mathrm{CO}_{2}$ concentrations are relatively homogeneous in all school yards. This trend agreed with the results reported by Lee and Chang (2000), but still lower than the results studied in Hongkong (max. 5900 ppm). Indoor $\mathrm{CO}_{2}$ concentrations are always higher than outdoor in all data sets (Fig. 3). The concentration levels of $\mathrm{CO}_{2}$ indoor and outdoor are $572.8 \pm 157.7 \mathrm{ppm}$ and $386.8 \pm 74.3 \mathrm{ppm}$, respectively. Indoor $\mathrm{CO}_{2}$ level in this study is lower than those found in Izmir, Turkey by 2009 $\pm 993 \mathrm{ppm}$ [15]. The highest levels of $\mathrm{CO}_{2}$ indoor and outdoor are $727.7 \mathrm{ppm}$ and 427.6 ppm at ELS-7, respectively. $\mathrm{CO}_{2}$ concentration levels are lower than AIS (Fig. 3). Lee and Chang (2000) found that $\mathrm{CO}_{2}$ concentration level is build-up when students start occupying the classroom. In other words, respiratory contributes the most to these values.

\subsection{Concentration level of VOCs}

The highest levels of VOCs indoor and outdoor are $330 \mathrm{ppb}$ and $925.2 \mathrm{ppb}$ at ELS-7 and 
ELS-9, respectively (Fig. 4). High indoor and outdoor concentrations of VOCs were found in schools located near commercial areas. ELS-4, ELS-6, ELS-7 as well as a school of a newly developed area, ELS-9 were monitored and found a relatively high VOCs level. The source of the VOCs might be from different types of products or production process besides VOCs from traffic.

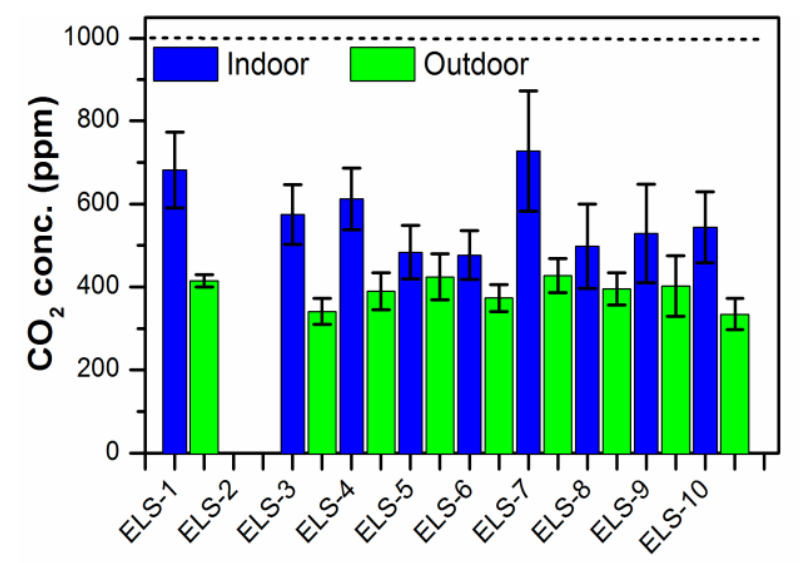

Indoor VOCs concentrations of these schools were higher than IAS of Hongkong. The rest of sites are having VOCs levels less than standards. It should be noted that indoor VOCs of some sites ELS-1, ELS-3, ELS-8 are higher than outdoor. It could be explained by the use of detergent for cleaning before monitoring time.

Fig. 3. Indoor and outdoor concentration of $\mathrm{CO}_{2}, \mathrm{NO}_{2}$ at schools; Dash lines (---) are IAS of $\mathrm{CO}_{2}(1000 \mathrm{ppm})$ [20] and $\mathrm{NO}_{2}(100 \mathrm{ppb})$ [3].

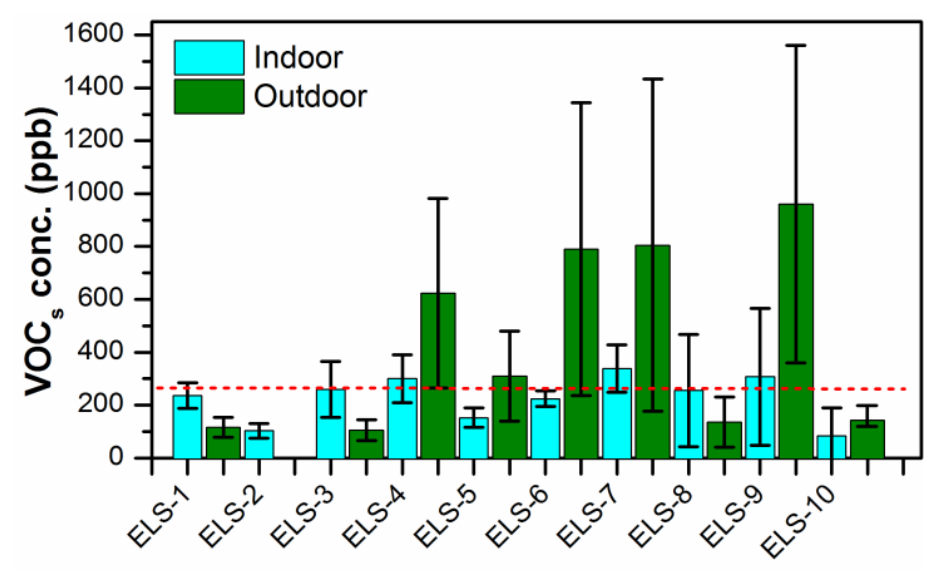

Fig. 4. Indoor and outdor concentration of VOCs at schools; Dash line (---) shows Hongkong IAS of VOCs (261 ppb) [13].

\section{Conclusions}

The study finds out that the major problem of air pollution at ten ELS in Hanoi is fine

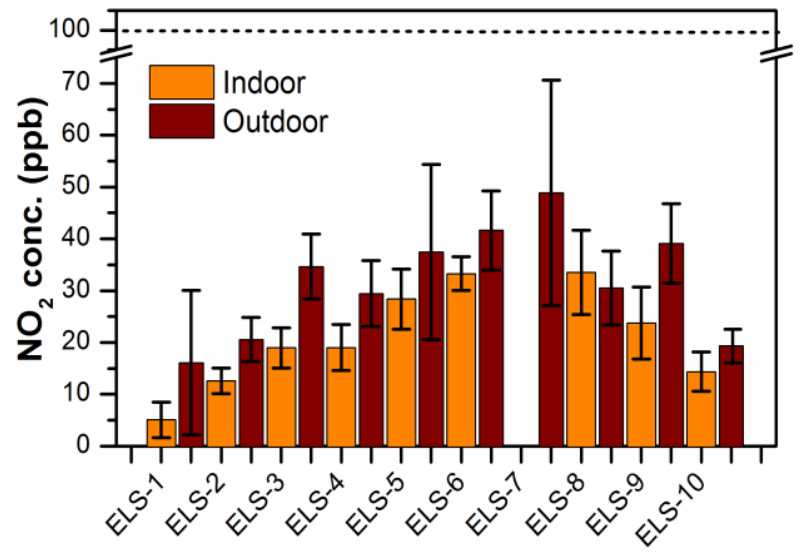


ELS-8, respectively. While the highest levels of $\mathrm{PM}_{2.5}$ and $\mathrm{PM}_{10}$ outdoor are $354.6 \mu \mathrm{g} / \mathrm{m}^{3}$ and $409.5 \mu \mathrm{g} / \mathrm{m}^{3}$ monitored at ELS-7, respectively. The highest levels of $\mathrm{CO}_{2}$ indoor and outdoor are $727.7 \mathrm{ppm}$ and $427.6 \mathrm{ppm}$ at ELS-7, respectively. The highest levels of $\mathrm{NO}_{2}$ indoor and outdoor are $66.6 \mathrm{ppb}$ and $97.7 \mathrm{ppb}$ at ELS-6 and ELS-7, respectively. The highest levels of VOCs indoor and outdoor are $330 \mathrm{ppb}$ and 925.2 ppb at ELS-7 and ELS-9, respectively. Hence, ELS-7 is a hotspot of air pollution where both indoor and outdoor parameters are highest of all. Two of the most impact sources to IAQ are traffic and residential activities of surrounding areas. Schools with shorter distance to the roads with more traffic intensity have higher air pollutant concentrations at indoor microenvironment.

At present, there is no specific study on IAQ in Vietnam. This pushed up a demand for researches of related issues as well as regulation concerning allowance standards for different categories of indoor usages. These are basis for improving IAQ and hence improving public health for citizens [20].

\section{References}

[1] K.R. Smith, J.M. Samet, I. Romieu, N. Bruce, Indoor air pollution in developing countries and acute lower respiratory infections in children, Thorax 55 (2000) 518-532. https://doi.org/10. 1136/thorax.55.6.518.

[2] J.M. Samet, M.C. Marbury, J.D. Spengler, Health effects and sources of indoor air pollution, American Review of Respiratory Disease: Part I 136 (1987) 1486-1508. https://doi.org/10.1164/ ajrccm/136.6.1486.

[3] $\mathrm{MOH}$, Indoor air quality standards - Draft version, Ministry of Health $(\mathrm{MOH})$, Hanoi, Vietnam, 2014 (in Vietnamese).

[4] H. Richard, E. Richard, H. Tim, School Indoor Air Quality Best Management Practices Manual, Washington State Department of Health, Olympia, Washington, USA (1995).

[5] N.E. Klepeis, W.C. Nelson, W.R. Ott, J.P. Robinson, A.M. Tsang, S. Paul, J.V. Behar, S.C. Hern, W.H. Engelmann, The National Human
Activity Pattern Survey (NHAPS): a resource for assessing exposure to environmental pollutants, Journal of exposure analysis and environmental epidemiology 11 (2001) 231-252. https://doi.org/ 10.1038/sj.jea.7500165.

[6] K.R. Smith, S. Mehta, The burden of disease from indoor air pollution in developing countries: comparison of estimates, International Journal of Hygiene and Environmental Health 206 (2003) 279-289.https://doi.org/10.1078/1438-4639-00224.

[7] USEPA, An introduction to indoor air quality (IAQ), United States Environmental Protection Agency (US EPA). USA (2014).

[8] WHO, Burden of disease from household air pollution for 2012, World Health Organization (WHO) (2014).

[9] VEA, Hanoi looking for pollution mitigation, Vietnam Environmental Administration (VEA) (2012) (in Vietnamese)

[10] H.A. Le, N.T. Huong, N.H. Phuc, Influence of traffic and wind speed on the $\mathrm{PM}_{10}, \mathrm{PM}_{2.5}$ levels at Truong Chinh street, Hanoi, VNU Journal of Science: Earth and Environmental Sciences 31 (2015) 186-192.

[11] V.T.Q. Truc, N.T.K. Oanh, Roadside BTEX and other gaseous air pollutants in relation to emission sources, Atmospheric Environment 41 (2007) 7685-7697. https://doi.org/10.1016/j.atm osenv.2007.06.003.

[12] MONRE, Environemtal status of Vietnam in period of 2011 - 2015, Hanoi, Vietnam, 2016 (in Vietnamese).

[13] S. Lee, M. Chang, Indoor and outdoor air quality investigation at schools in Hong Kong, Chemosphere 41 (2000) 109-113. https://doi.org/ 10.1016/S0045-6535(99)00396-3.

[14] W. Yang, J. Sohn, J. Kim, B. Son, J. Park, Indoor air quality investigation according to age of the school buildings in Korea, Journal of environmental management 90 (2009) 348-354. https://doi.org/10.1016/j.jenvman.2007.10.003.

[15] O. Ekren, Z.H. Karadeniz, İ. Atmaca, T. UgranliCicek, S.C. Sofuoglu, M. Toksoy, Assessment and improvement of indoor environmental quality in a primary school, Science and Technology for the Built Environment 23 (2017) 391-402. https://doi.org/10.1080/23744731.2016. 1251288 .

[16] H.A. Le, L.T. Linh, Assessment of indoor and ambient air pollution at complex buildings in Hanoi, VNU Journal of Science: Earth and Environmental Sciences 35 (2019) 85-92. https:// doi.org/10.25073/2588-1094/vnuees.4393. 
[17] H.A. Le, D.M. Cuong, N.T.K. Anh, Particulate matter $\left(\mathrm{PM}_{10}, \mathrm{PM}_{2.5}, \mathrm{PM}_{1}\right)$ indoor pollution by using different fuel materials, VNU Journal of Science: Earth and Environmental Sciences 34 (2018) 28-34. https://doi.org/10.25073/2588-1094/ vnuees.4284.

[18] H.A. Le, D.T. Xuan, Study on personal exposure to black carbon while using different modes of transport in Truong Chinh street, Hanoi, VNU Journal of Science: Natural Sciences and Technology 31 (2015) 179-185.
[19] ASHRAE, Standard 62.1-2019, Ventilation for Acceptable Indoor Air Quality, American National Standards Institute, Atlanta, Georgia 30329 US, 2019.

[20] M.S. Crandall, W.K. Sieber, The National Institute for Occupational Safety and Health indoor environmental evaluation experience. Part one: building environmental evaluations, Applied Occupational and Environmental Hygiene 11 (1996) 533-539. https://doi.org/10. 1080/1047322X.1996.10389370. 